\section{NUMERICAL SOLUTION FOR IMMUNOLOGY TUBERCULOSIS MODEL USING RUNGE KUTTA FEHLBERG AND ADAMS BASHFORTH MOULTON METHOD}

\author{
Usman Pagalay*, Muhlish
}

Department of Mathematics State Islamic University of Maulana Malik Ibrahim Malang, Indonesia
Article history

Received

4 July 2015

Received in revised form

11 November 2015

Accepted

12 March 2016

*Corresponding author usmanpagalay@yahoo.co.id

\section{Graphical abstract}

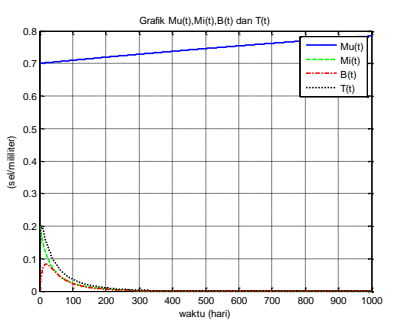

\begin{abstract}
The Immunology tuberculosis model that has been formulated by (Ibarguen, E., Esteva, L., \& Chavez, L, 2011) in the form of a system of nonlinear differential equations first order. In this study, we used to Runge Kutta Fehlberg method and Adams Bashforth Moulton method. This study has been obtained numerical solution of the model. The results showed that the relative error obtained from the Adams Bashforth Moulton method is smaller when compared with the Runge Kutta Fehlber method. There are two methods has a high accuracy in solving systems of nonlinear differential equations.
\end{abstract}

Keywords: Runge Kutta Fehlberg, Adams Bashforth Moulton, Immunology of Tuberculosis Models

(C) 2016 Penerbit UTM Press. All rights reserved

\subsection{INTRODUCTION}

The immunology celluler of tuberculosis models shaped system of nonlinear differential equations, thus requiring a special method to determine the solution. Settlement system of nonlinear differential equations is generally difficult to solved [1]. In this study, we used to Runge Kutta Fehlberg (RKF) method and Adams Bashforth Moulton (ABM) method for solving systems of nonlinear differential equations.

RKF method is a one-step numerical methods with high accuracy while $A B M$ method is a numerical method-shaped two-step predictor corrector with good accuracy.

This study aims to determine how the numerical solution of the model of Tuberculosis immunology with RKF method and ABM method, as well as how to compare the two methods.

The mathematical models used to understand Mycobacterium Tuberculosis (Mtb) interaction with the immune system in the lung include: bacterial, $T$ lymphocytes and macrophages.

\subsection{LITERATURE REVIEW}

In a scientific paper titled A Mathematical for Celluler Immunology of Tuberculosis obtained mathematical models of cellular immunology at the tuberculosis, which consists of four dependent variables. The fourth variable is the population of uninfected macrophages, macrophage population is infected, the bacteria population $\mathrm{Mtb}$ and T cell populations. Let $M U(t), M i(t), B(t)$ and $T(t)$ of each state the number of population at the time $t$, then the mathematical model of the cellular immunology of tuberculosis can be described as follows:

$$
\begin{aligned}
& \frac{d M u(t)}{d t}=\mu_{U}-\mu_{U} M u(t)-\beta B(t) M u(t) \\
& \frac{d M i(t)}{d t}=\beta B(t) M u(t)-\alpha_{T} M i(t) T(t)-\mu_{T} M i(t) \\
& \frac{d B(t)}{d t}=r M i(t)-\gamma_{U} M u(t) B(t)-\mu_{B} B(t) \\
& \frac{d T(t)}{d t}=k_{1} M i(t)-k_{1} M i(t) T(t)-\mu_{T} T(t)
\end{aligned}
$$


Where $\beta_{v} \alpha_{T}, \mu_{U}, \mu_{l}, \mu_{B}, \gamma_{U}, r$, and $k_{1}$ everything is a positive coefficient. $\beta$ shows the rate of bacterial infection, $\alpha_{T}$ indicating the growth rate $T$ cell of the infected macrophages, $\mu_{U}$ is uninfected macrophage death rate, $\mu_{T}$ as the death of infected macrophages, $\mu_{B}$ showing the natural death rate of bacteria, $\gamma_{U}$ as the rate of death due to bacteria-infected macrophages, $r$ average number production of bacteria in infected macrophages and $k_{1}$ are the growth rate T cells [2].

\subsection{METHODOLOGY}

Research methods used by the author in this study are the study of literature or library research is to examine and study the books, journals and other references that support the research. Runge-Kutta method is a numerical method one-step, because this method requires only one previous point to compute the new value. Runge-Kutta method is often used Runge-Kutta method of order four. There are several types of Runge-Kutta methods that depend on the value of $n$ is used. For $n=1$ is called the Runge Kutta method of order one, while the authors used a method Fehlberg Runge Kutta order 4 and 5 (RKF 45). The RKF 45 method belonging to the family of Runge-Kutta method of order 4 , but has an accuracy up to order 5. Accuracy This is possible because of the high RKF 45 method has 6 pieces of calculation constants whose role is to update the solution to order 5 [3].

Formulations of the Runge Kutta Fehlberg method (RKF 45) are as follows:

4th Order Formula:

$$
y_{i}+1=y_{i}+\frac{25}{216} k_{1}+\frac{1408}{256} k_{a}+\frac{2197}{4104} k_{4}+\frac{1}{5} k_{5}
$$

5th Order Formula:

$\hat{y}_{i+1}=y_{i}+\frac{16}{195} k_{1}+\frac{6656}{12825} k_{a}+\frac{28561}{56497} k_{4}-\frac{9}{50} k_{5}+$ $\frac{2}{55} k_{6}$

Where $\quad k_{1}=h f\left(x_{i}, y_{i}\right), \quad k_{2}=h f\left(x_{i}+\frac{1}{4} h s y_{i}+\frac{1}{4} k_{1}\right)$, $k_{a}=h f\left(x_{i}+\frac{a}{g} h_{s} y_{i}+\frac{a}{a 2} k_{1}+\frac{9}{a 2} k_{2}\right)$.

$k_{4}=h f\left(x_{i}+\frac{12}{12} h_{s} y_{i}+\frac{1912}{2197} k_{1}-\frac{7200}{2197} k_{2}+\frac{7296}{2197} k_{a}\right)$, $k_{5}=h f\left(x_{i}+h, y_{i}+\frac{439}{216} k_{1}-8 k_{2}+\frac{a 860}{513} k_{a}-\frac{845}{4104} k_{4}\right)$. $k_{6}=h f\left(x_{i}+\frac{1}{2} h_{s} y_{i}-\frac{8}{27} k_{1}+2 k_{2}-\frac{8544}{2565} k_{a}+\frac{1859}{4104} k_{4}-\right.$ $\left.\frac{11}{40} k_{5} h\right)$

RKF 45 relative error is the difference $y_{\mathrm{i}}$ in the order of 4 th and 5th order, so formulated:

$\hat{y}_{i+1}-y_{i+1}=\frac{1}{a 60} k_{1}-\frac{128}{4275} k_{a}-$

$\frac{2197}{75240} k_{4}+\frac{1}{50} k_{5}+\frac{2}{55} k_{6}$
Settlement of ordinary differential equations using Adams Bashforth Moulton method is the process of looking for value function $y(x)$ at point $x$ certain of nonlinear ordinary differential equations of first order $y^{\prime}=f(x, y)$ and the initial value $y\left(x_{0}\right)=y_{0}$ that are known to predict the predictor equation and make corrections to the equation corrector. Initial values required in Adams Bashforth Moulton method fourth order can be obtained from one-step method (onestep method). So as to obtain a combination of good results, Runge-Kutta method of order-4 can be used together Adams Bashforth Moulton method of $4^{\text {th }}$ order.

Formulation $A B M$ Method $4^{\text {th }}$ order is as follows:

Predictor ABM Formula:

$$
\begin{aligned}
& p y_{i+1}=y_{i}+\frac{n}{24}\left(55 y_{n}^{n}-59 y_{n-1}^{n}+37 y_{n-2}^{n}-\right. \\
& \left.9 y_{n-a}^{n}\right)
\end{aligned}
$$

Corrector ABM Formula:

$y_{i+1}=y_{i}+\frac{h}{24}\left(9 p y_{n+1}^{s}+19 y_{n}^{n}-5 y_{n-1}^{n}+\right.$

$\left.y_{n-2}^{s}\right)$

With $y_{i}^{\prime}=f\left(x_{i v}, y_{i}\right), \forall_{i}=3,4, \ldots$

The relative error $A B M$ method $4^{\text {th }}$ order has been formulated as follows:

$E_{A B M}=-\frac{19}{270}\left(y_{i+1}-p y_{i+1}\right)=D_{i+1}$ (Bronson, R. dan Costa, G.B, 2007).

\subsection{RESULTS AND DISCUSSION}

Parameters and initial values are used as in Table 1. Completion of the system of equations (1) above by using RKF 45 can be performed with the following steps:

Identification parameter values and initial values of the system of differential equations (1) Mu variable $\mathrm{Mu}(0), \operatorname{Mi}(0), B(0)$ and $T(0)$.

Determining the value of $t$ (time), which will be determined along with the completion magnitude $h$ (step size)

Determining the method formulation R KF 45 for the system of equations (1)

Calculate the variables contained in the formula RKF 45 by using a predetermined formula, the variable $k_{1}$ $-k_{6}, m_{1}-m_{6}, n_{1}-n_{6}$ and $p_{1}-p_{6}$.

Calculating $M U i+1, M i+1, B i+1$ and $T i+1$ by substituting the variables that have been obtained in step 4 into the formulation methods of RKF 45 in step 3

Based on the above steps, in this study the authors determine the amount of $t$ (time) to be resolved is $t=$ $1000 \mathrm{~h}$ (step size) $=0.1$ and $i$ starts from 0 to 1000 . Then, as the value of $k_{1}-k_{6}, m_{1}-m_{6}, n_{1}-n_{6}$ and $p_{1}$ $P \circ$ are known, then substituted into the equation (2) 
and (3) so that the first iteration calculations can be performed as follows:

RKF $4^{\text {th }}$ Order calculation:

$M u_{0+1}=M u_{0}+\frac{25}{216} k_{1}+\frac{1408}{256} k_{a}+\frac{2197}{4102} k_{4}-\frac{1}{5} k_{5}$ $M_{u_{1}}=0.7+\frac{25}{216}(0,0000099)+\frac{1408}{256}(0,0000989997725)+\frac{2197}{4102}(0.0000098996697851)-\frac{1}{5}(0,0000098999672671)$

$M u_{1}=0.7000098998$

RKF $5^{\text {th }}$ Order calculation:

$\widehat{M} u_{0+1}=M u_{0}+\frac{16}{135} k_{1}+\frac{6656}{12825} k_{3}+\frac{28561}{56437} k_{4}-\frac{9}{50} k_{5}+\frac{2}{55} k_{6}$

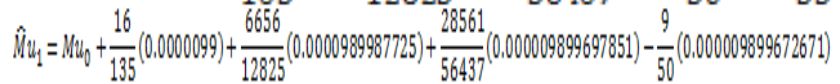
$+\frac{2}{55}(0.000009899836334)$

$\widehat{M} u_{0+1}=7000098992$

Solutions Mi (t), B (t) and $Q(t)$ can be solved in the same manner as above, after for the $2^{\text {nd }}$ iteration until the 1000 calculation is done with the help of matlab program in order to obtain a system solution with RKF 45 as per shown in Table 1.

Table 1 Solution system of equations (1) with the RKF 45 method

\begin{tabular}{|c|c|c|c|c|}
\hline \multirow{2}{*}{$i$} & \multirow{2}{*}{$t$} & \multirow{2}{*}{$\begin{array}{l}\text { Va } \\
\text { rib } \\
\text { el }\end{array}$} & \multicolumn{2}{|c|}{ Solution RKF } \\
\hline & & & Orde-4 & Orde-5 \\
\hline \multirow{4}{*}{0} & \multirow{4}{*}{0.1} & $M u_{i}$ & $\begin{array}{c}0.70000989 \\
98\end{array}$ & 0.000098992 \\
\hline & & $M i_{i}$ & $\begin{array}{c}0.19977057 \\
48\end{array}$ & 0.1997705898 \\
\hline & & $B_{i}$ & $\begin{array}{c}0.00109534 \\
48\end{array}$ & 0.0010952763 \\
\hline & & $T_{\mathfrak{i}}$ & $\begin{array}{c}0.00948748 \\
49\end{array}$ & 0.0094869002 \\
\hline \multirow{4}{*}{1000} & \multirow{4}{*}{100} & $M u_{i}$ & $\begin{array}{c}0.70973890 \\
785489 \\
\end{array}$ & 0.70098835331038 \\
\hline & & $M i_{i}$ & $\begin{array}{c}0.02534013 \\
996889 \\
\end{array}$ & 0.15219300148588 \\
\hline & & $B_{i}$ & $\begin{array}{c}0.02387361 \\
413303\end{array}$ & 0.06859884960258 \\
\hline & & $T_{\mathrm{i}}$ & $\begin{array}{c}0.03746338 \\
277466\end{array}$ & 0.19141029376893 \\
\hline \multirow{4}{*}{10000} & \multirow{4}{*}{1000} & $M u_{i}$ & $\begin{array}{c}0.78432660 \\
796594\end{array}$ & 0.78432193451241 \\
\hline & & $M i_{i}$ & $\begin{array}{c}0.00000092 \\
745234\end{array}$ & 0.00000092929546 \\
\hline & & $B_{\hat{i}}$ & $\begin{array}{c}0.00000073 \\
025277\end{array}$ & 0.00000073170851 \\
\hline & & $T_{\mathrm{i}}$ & $\begin{array}{c}0.00000140 \\
963308\end{array}$ & 0.00000141243443 \\
\hline
\end{tabular}

Completion of the system of equations (1) by using the ABM can be done with the following steps:

1. Identification parameter valuesand initial values of the system of differential equations (1) $\mathrm{Mu}$ variable $\mathrm{MU}(0), \mathrm{Mi}(0), \mathrm{B}(0)$ and $\mathrm{T}(0)$.

2. Determining the value of $t$ (time), which will be determined along with the completion magnitude $h$ (step size)
3. Calculating four initial solution

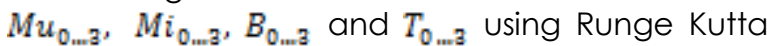
$4^{\text {th }}$ Order method.

4. Determining the value of $f_{n}, f_{n-1}, f_{n-2}$ and $f_{n-a}$ with $n=3,4, \ldots$ defined as follows:

$f_{n-1}=f_{0}=f\left(t_{0}, M u_{0}, M i_{0}, B_{0}, T_{0}\right)$

$f_{n-2}=f_{1}=f\left(t_{1}, M u_{1}, M i_{1}, B_{1}, T_{1}\right)$

$f_{n-1}=f_{2}=f\left(t_{2}, M u_{2}, M i_{2}, B_{2}, T_{2}\right)$

$f_{n}=f_{a}=f\left(t_{\mathrm{a}}, M u_{\mathrm{a}}, M i_{\mathrm{a}}, B_{\mathrm{a}}, T_{\mathrm{a}}\right)$

For value $g_{n}, j_{n}$ and $k_{0}$ do the same steps as in $f_{n}$

5. Determine the numerical solution with an predictors used ABM method $4^{\text {th }}$ Order.

6. Calculating the value of $f_{n+1}, g_{n+1}, j_{n+1}$ dan $k_{n+1}$.

7. From the calculation of step 6 further calculates a numerical solution using the method corrector $A B M-4^{\text {th }}$ order.

8. Corrector $A B M$ method iterated on $n$ to meet,

$\frac{19}{270} \frac{\left|y_{n+1}-p y_{n+1}\right|}{y_{n+1}}<\varepsilon$ for $n=3,4,5, \ldots$ and $\varepsilon$ is the dismissal of the desired criteria, namely $\varepsilon=5 \times 10^{-8}$.

Based on the above steps, in this study the authors determine the amount of $t$ (time) to be resolved is $t=$ $1000 \mathrm{~h}$ (step size) $=0.1$ and $i$ starts from 0 to 1000 . Furthermore, after the four initial solution and value $f_{n}, g_{n}, j_{n}$ and $k_{n}$ with $\mathrm{n}=1,2,3$ known, then substituted into the equation (5) and (6) so that the first iteration calculations can be performed as follows:

Calculation of predictor $A B M 4^{\text {th }}$ Order:

$p M u_{n+1}=M u_{n}+\frac{i n}{24}\left(55 f_{n}-59 f_{n-1}+37 f_{n-2}-\right.$

$9 f_{n-8}$ )

$p M u_{a+1}=M u_{a}+\frac{h}{24}\left(55 f_{a}-59 f_{2}+37 f_{1}-9 f_{0}\right)$

Calculation of correcctor $A B M 4^{\text {th }}$ Order:

$M u_{n+1}=M u_{n}+\frac{n}{24}\left(9 f_{n+1}+19 f_{n}-5 f_{n-1}+f_{n-2}\right)$

$M u_{a+1}=M u_{a}+\frac{h}{24}\left(9 f_{4}+19 f_{a}-5 f_{2}+f_{1}\right)$

Solutions $\mathrm{Mi}(\mathrm{t}), \mathrm{B}(\mathrm{t})$ and $\mathrm{T}(\mathrm{t})$ can be solved in the same manner as above, after for the $2^{\text {nd }}$ iteration until the 1000 calculation is done with the help of matlab program in order to obtain a system solution equation (1) with ABM method as shown in Table 2. 
Table 2 Solution system of equations (1) using ABM method

\begin{tabular}{|c|c|c|c|c|}
\hline \multirow{2}{*}{ I } & \multirow{2}{*}{$t$} & \multirow{2}{*}{$\begin{array}{l}\text { Vari } \\
\text { bel }\end{array}$} & \multicolumn{2}{|c|}{ Solution $\mathrm{ABM}$} \\
\hline & & & predictor & corrector \\
\hline \multirow{4}{*}{4} & \multirow{4}{*}{0.5} & $M u_{i}$ & 0.7000049524 & 0.7000049520 \\
\hline & & $M i_{i}$ & 0.1989761780 & 0.1989761783 \\
\hline & & $B_{i}$ & 0.00432527462 & 0.004325274544 \\
\hline & & $T_{i}$ & 0.03556886560 & 0.03556887438 \\
\hline \multirow{4}{*}{$\begin{array}{c}100 \\
0\end{array}$} & \multirow{4}{*}{100} & $M u_{i}$ & 0.70973840206275 & 0.70973840206275 \\
\hline & & $M i_{i}$ & 0.02551775753494 & 0.02551775753494 \\
\hline & & $B_{i}$ & 0.02405045835086 & 0.02405045835086 \\
\hline & & $T_{i}$ & 0.03771836083017 & 0.03771836083016 \\
\hline \multirow{4}{*}{$\begin{array}{c}100 \\
00\end{array}$} & \multirow{4}{*}{$\begin{array}{c}100 \\
0\end{array}$} & $M u_{i}$ & 0.78432284958716 & 0.78432284958716 \\
\hline & & $M i_{i}$ & 0.00000094967835 & 0.00000094967835 \\
\hline & & $B_{i}$ & 0.00000074775997 & 0.00000074775997 \\
\hline & & $T_{i}$ & 0.00000144341432 & 0.00000144341432 \\
\hline
\end{tabular}

Figure 1 shows the population $(\mathrm{Mu}),(\mathrm{Mi}),(\mathrm{B})$ and $(T)$ starting on day 0 with parameter values and initial values that have been presented in Table 1. The initial value $(M u(0)=0.7),(M i(0)=0.2)$, $(B(0)=0)$, and $(T(0)=0)$, constantly moving up the growth charts $(\mathrm{Mu})$ is beginning on day 1 until day 100 , which reached 0.8 cells / $\mathrm{ml}$, while the chart growth (Mi) continuous that started moving down on day 1 until day 1000 reached 0002 cells / ml. The movement of growth charts $(B)$ and $(T)$ has increased to 15 the next day to a continuous decline until today to 1000 which reached 0.002 cells / ml. This graph according to the results obtained Ibarguen, E., Esteva, L., \& Chavez, L, 2011.

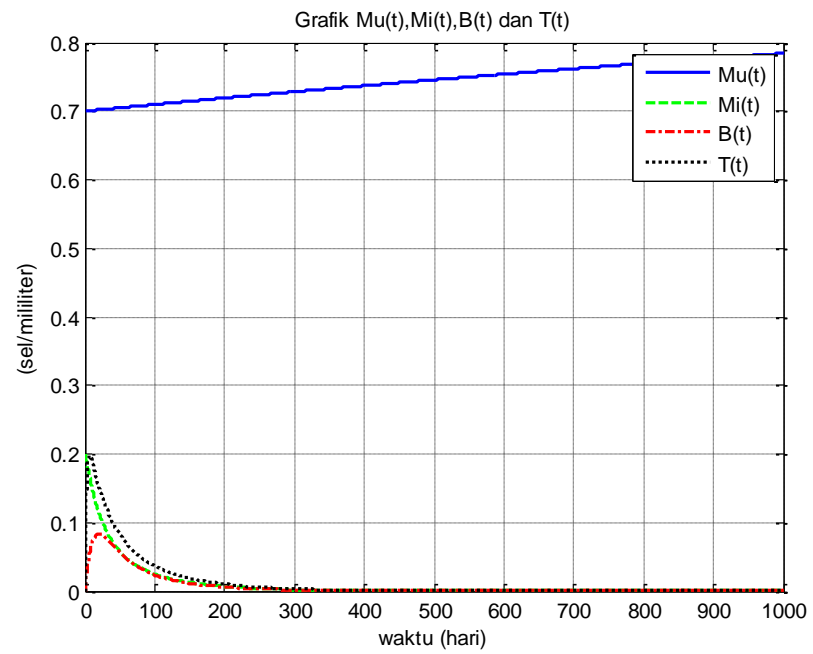

Figure 1 Graph $M u(t), M i(t), B(t)$ and $T(t)$ at $t=1000$

\subsection{CONCLUSION}

Based on the results of the discussion, it can be concluded that in solving the system of nonlinear differential equations in the model of the cellular immunology of tuberculosis with Runge Kutta Fehlberg method can be done in several stages as in the description above discussion. Completion of numerical of cellular immunology of tuberculosis with Adams Bashforth Moulton method can be done by several stages as in the description above discussion.

\section{Acknowledgment}

The authors would like to thank the faculty of science and technology, Islamic State University of Malang and friend who helped writing this paper.

\section{References}

[1] Bronson, R. dan Costa, G. B. 2007. Scaum's Outlines: Differential Equations. Jakarta: Erlangga.

[2] Capra, S. \& Canale, R. 2010. Numerical Methods for Engineers. New York: The McGraw-Hill Companies.

[3] Ibarguen, E., Esteva, L., \& Chavez, L. 2011. A Mathematical Model for Celluler Immunology of Tuerculosis. Mathematical Biosciences and Engineering. 4: 973-986.

[4] Mathews \& Kurtis. 2004. Numerical Methods Using Matlab. Fourth Editions. New Jersey: The Prentice hall, Inc. 